\title{
Computer Aided Engineering for Ferrite Products
}

\author{
H. Rikukawa and I. Sasaki \\ FDK Corporation, Advanced Technology Laboratories, 2281 Washizu, Kosai, Shizuoka 431-04, Japan
}

\begin{abstract}
We have been applying CAE (Computer Aided Engineering) to the development, design and manufacture of ferrite products. This paper introduces examples of the $\mathrm{CAE}$. Heat generation analysis for the development of a new deflection yoke, the design of a rotary transformer by utilizing $\mathrm{CAE}$ and oxygen concentration analysis in a firing kiln of $\mathrm{Mn}-\mathrm{Zn}$ ferrite are mentioned. We have been confirmed in the effectiveness of CAE by these examples.
\end{abstract}

\section{INTRODUCTION}

According to an improvement of performance of computer, computer simulation, which is a virtual experiment using numerical analysis by solving dominant formulae for a specific phenomenon, has become to be applied to a wide range of development, design and manufacture of all industrial products. The method for carrying out these engineering activities using computer simulation is called CAE (Computer Aided Engineering).

We have been applying CAE to the development, design and manufacture of ferrite products. This paper introduces several topics of the application of $\mathrm{CAE}$ to the ferrite products.

\section{EXAMPLES OF CAE}

\subsection{Heat generation analysis of a deflection yoke}

A deflection yoke has become to operate under severe conditions of high frequency and high deflection power with the progress of television and display monitor technology, so that heat generation from the deflection yoke has become increasingly a serious problem. Conventional prototype repetition and testing offer few good solution to the development of a new deflection yoke. Then we have applied CAE to the heat generation analysis of deflection yokes.

Using magnetic field analysis of the deflection yoke by the magnetic moment method[1], the magnetic flux density in the ferrite core and windings can be calculated. The heat generation from the core is obtained on referring to core loss data at calculated magnetic flux density and operating frequency. The DC copper loss is simply calculated using Ohm's law. The AC copper loss is also calculated as eddy current loss caused by AC magnetic flux crossing to the windings.

These analysis clarifies the influence of core loss and winding condition on the heat generation from the deflection yoke, and provides technical data for the development of new deflection yokes[2].

\subsection{Design of a rotary transformer}

When designing a rotary transformer, the size of trenches housing windings and short rings on the ferrite core must be determined according to the required electric properties and the given dimensions of appearances. Instead of conventional prototype repetition and testing, the magnetic field analysis has been applied to the design of rotary transformers.

A rotary transformer can be approximated with having axisymmetric shape. The self inductance and mutual inductance of each channels are obtained by axisymmetric magnetic field analysis with the boundary element method[3]. The self capacitance and mutual capacitance are calculated with simple formulae used for designing transformers[4]. The resistance is considered only to consist of the winding resistance. Using a simple equivalent circuit model for the transformer, the set up inductance, leakage inductance, coupling factor and cross-talk at operating frequency can be calculated analytically. The suitable design can be found quickly to modify the calculating conditions (usually the size of trenches). Table 1 shows an example of comparison of 
the calculated properties of transformer, which is designed with the calculation to satisfy specifications, with measured results of the product manufactured in accordance with the design. The calculation is accurate enough for practical usage.

Table 1: Comparison of the calculated values with measured results of a two channels rotary transformer. (Dimensions: outer diameter $31.2 \mathrm{~mm}$, inner diameter $18.4 \mathrm{~mm}$, height $2.5 \mathrm{~mm}$, gap length $50 \mu \mathrm{m}$ )

\begin{tabular}{|l|c|c|c|c|c|c|c|c|}
\hline & \multicolumn{2}{|c|}{ Set up inductance } & \multicolumn{2}{c|}{ Leakage inductance } & \multicolumn{2}{c|}{ Coupling factor } & \multicolumn{3}{c|}{ Cross-talk } \\
\hline Unit/Frequency & \multicolumn{1}{|c|}{$\mu \mathrm{H} / 1 \mathrm{MHz}$} & \multicolumn{2}{|c|}{$\mu \mathrm{H} / 1 \mathrm{MHz}$} & \multicolumn{3}{|c|}{$/ 1 \mathrm{MHz}$} & \multicolumn{2}{c|}{$\mathrm{dB} / 5 \mathrm{MHz}$} \\
\hline Cannel & $\mathrm{CH} \mathrm{1}$ & $\mathrm{CH} 2$ & $\mathrm{CH} \mathrm{l}$ & $\mathrm{CH} 2$ & $\mathrm{CH} \mathrm{1}$ & $\mathrm{CH} 2$ & $\mathrm{CH} 1$ & $\mathrm{CH} 2$ \\
\hline Specifications & $45 \pm 15 \%$ & $45 \pm 15 \%$ & $<3.6$ & $<3.6$ & $>0.96$ & $>0.96$ & $<-25$ & $<-25$ \\
\hline Calculated values & 45.45 & 45.51 & 2.50 & 2.48 & 0.972 & 0.972 & -33.0 & -32.0 \\
\hline Measured results & 46.13 & 46.41 & 2.43 & 2.70 & 0.973 & 0.971 & -32.3 & -31.3 \\
\hline
\end{tabular}

\subsection{Oxygen concentration analysis in a firing kiln of $\mathrm{Mn}-\mathrm{Zn}$ ferrite}

Oxygen concentration in a firing kiln is known to have an important role on the quality of $\mathrm{Mn}-\mathrm{Zn}$ ferrite. In order to maintain constant $\mathrm{Fe}^{2+}$ content during cooling of firing process, the oxygen concentration must be continuously decreased according to a logarithmic relation, i.e. $\log \mathrm{Po}_{2}=\mathrm{a}-\mathrm{b} / \mathrm{T}$, where $\mathrm{Po}_{2}$ is oxygen partial pressure, $\mathrm{T}$ is the absolute temperature, a and $\mathrm{b}$ are constant. If the oxygen concentration in a firing kiln deviates from this relation, the quality of $\mathrm{Mn}-\mathrm{Zn}$ ferrite deteriorates.

It is possible to control strictly the oxygen concentration according to the logarithmic relation in the computer controlled small batch kiln for research and development usage[5]. But in a tunnel kiln for mass production, it is impossible to control the oxygen concentration, because it is determined by gas flow, and we could not know where and how the gas flows.

In order to find the optimum gas input and the structure of firing kiln, we calculated the distribution of oxygen concentration using computational fluid dynamics[6]. Fig.1 shows an example of the gas flow on a cross section of a tunnel kiln. According to the result of these calculations, we improved the stracture of the tunnel kiln. As the result, the suitable oxygen concentration could be obtained in wide position of the kiln, so that the quality of $\mathrm{Mn}-\mathrm{Zn}$ ferrite could be improved dramatically.

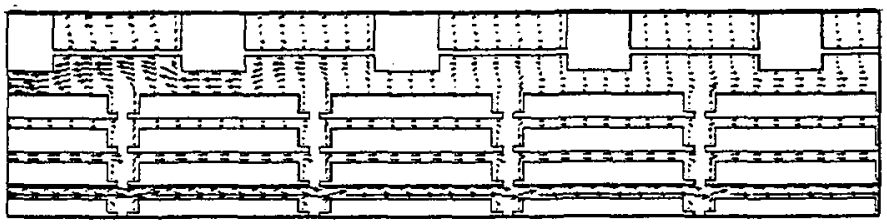

Figure 1: Gas flow on a cross section of a tunnel kiln.

\section{CONCLUSION}

Utilizing CAE, we can carry out virtual measurements of which it is impossible to measure actually. As the examples, the distribution of heat generation from deflection yokes and the gas flow and oxygen concentration in a tunnel kiln of Mn-Zn ferrite were mentioned in this paper. It has been possible to make improvements according to the results of these virtual measurements.

Moreover, it has been possible to design a new rotary transformer by the CAE without any trial production. Therefore, changes, additions and corrections of the specifications of rotary transformer can be followed easily and quickly, that are frequently required in a new design of video tape recorder.

We have been confirmed in the effectiveness of the CAE by these examples. The role of CAE is considered to be more important to the future ferrite industry.

\section{References}

[1] Newman M. J., Trowbridge C. W. and Turner L. R., "GFUN: An Interactive Program as an Aid to Magnet Design", Rutherford Lab., RPP/A94 (1972).

[2] Ikegami K., Masuda Y., Takei H. and Maeda T., "Low Loss of Mg-Mn-Zn Ferrite for Deflection Yoke" to be published in the Proceedings of ICF 7 .

[3] Rikukawa H., Atsumi N., Sasaki I. and Tanaka M., "Boundary Element Analysis of Axisymmetric Magnetic Field Problem", $6^{\text {th }}$ Symposium on the Application of FEM to Electrical and Electronics Engineering, Tokyo, Mar. 1985, pp. $75-80$.

[4] Snelling E. C., Soft Ferrites $2^{\text {nd }}$ Edition (Butterworths, London, 1988) pp. 330-335.

[5] Rikukawa H. and Sasaki I., "On the Sintering Atmosphere of Mn-Zn Ferrites", ICF 4, San Francisco, Oct.-Nov. 1984, F. F. Y. Wang Ed., Advances in Ceramics Volume 15 (The American Ceramic Society, Columbus, Ohio, 1986) pp. $215-219$.

[6] Hakamada K., Fujimoto K., Rikukawa H. and Sasaki I., "Numerical Analysis for Atmosphere in a Tunnel Kiln", Thermal Engineering Conference '93, Tokyo, Oct. 1993, pp. 230-232. 